managing knee pain, understanding it can be improved though self-management. However, too much information was provided in a short time-span and it was difficult to fit exercises into their daily routine.

Conclusion: Delivery of a non-pharmacological intevention by a nurse is feasible within a research setting. Most components of the intervention were delivered as intended, except for advice about the use of adjunctive treatment.

Acknowledgments: This research was funded by the NIHR Nottingham BRC and Pain Centre Versus Arthritis

Disclosure of Interests: Polykarpos Angelos Nomikos: None declared, Amy Fuller: None declared, Michelle Hall: None declared, Bonnie Millar: None declared, Reuben Ogollah: None declared, Michael Doherty: None declared, Roshan Nair Speakers bureau: Financial support from pharmaceutical companies (Biogen and Novartis) to present lectures at events related to psychological support for people with multiple sclerosis (Speaker's bureau)., David Walsh Grant/research support from: 2016: Investigator-led grant from Pfizer Ltd (ICRP) on Pain Phenotypes in RA; non-personal financial disclosure (payment to University)., Consultant of: DAW has undertaken paid consultancy to Pfizer Ltd, Eli Lilly and Company and GSK Consumer Healthcare., Paid instructor for: 2019: Consultancy to Love Productions; consultancy on programme design, contribution to programme content on self-management of chronic pain (payments to University)

2019: Consultancy to AbbVie Ltd; 13.06.19; presentation on RA pain at EULAR, Madrid, and webinar (payments to University).

2019: Consultancy to Eli Lilly and Company Ltd. 06.06.19 Centre for Collaborative Neuroscience, Windlesham, Surrey, UK (payment to University).

2019: Consultancy to Pfizer (payment to University).

2018: Consultancy to Pfizer. 07.12.18. USA. 1 day. Tanezumab (payment to University).

2018: Consultancy to Pfizer. 23.11.18. Manchester UK. 1 day. Tanezumab (payment to University).

2018: Consultancy to Pfizer. 1.11.18. Skype. 4h. Tanezumab (payment to University).

2018: Consultancy to GlaxoSmithKline Plc. 1 day. Pain in RA and anti-GM-CSF (payment to University).

2018: Consultancy to Pfizer Ltd; Presentation at OARSI; non-personal financial disclosure (payment to University)

2018: Consultancy to Pfizer Ltd; Patient preference study; non-personal financial disclosure (payment to University)

2017: Consultancy to Pfizer Ltd; personal financial disclosure

2017: Consultancy to Pfizer Ltd through Nottingham University; non-personal financial disclosure (payment to University).

2015: Consultancy to GSK Consumer Healthcare; personal financial disclosure., Speakers bureau: 2019: Irish Society of Rheumatology: speaker fees (personal pecuniary), Ana Valdes Grant/research support from: Awarded a grant from Pfizer, Abhishek Abhishek: None declared

DOI: 10.1136/annrheumdis-2020-eular.1393

\section{FRI0629-HPR USE AND USABILITY OF THE DR. BART APP AND ITS RELATION WITH CLINICAL OUTCOMES IN PEOPLE WITH KNEE AND/OR HIP OSTEOARTHRITIS}

$\underline{T}$ Pelle ${ }^{1,2}$, J. Van der Palen ${ }^{3}$, F. Van den Hoogen ${ }^{1,2}$, K. Bevers ${ }^{1}$, C. Van den Ende ${ }^{1,2}$. ${ }^{1}$ Sint Maartenskliniek, Rheumatology, Nijmegen, Netherlands; ${ }^{2}$ Radboudumc, Rheumatology, Nijmegen, Netherlands; ${ }^{3}$ University of Twente, Research Methodology, Enschede, Netherlands

Background: Self-management is of paramount importance in non-surgical treatment of knee and/or hip osteoarthritis(OA). Modern technologies offer the possibility to support self-management $24 / 7$. We developed an e-self-management application (dr. Bart app) for people with knee and/or hip OA.

Objectives: To document the use of the dr. Bart app and its relation with health care utilization and clinical outcomes in people with knee and/or hip OA.

Methods: For this study we used back end data of the first 26 weeks from the intervention group ( $\mathrm{N}=214$ ) of a RCT (total included 427 ) examining the effectiveness of the dr. Bart app. Participants were included based on self-reported knee and/or hip OA. In figure 1 the theoretical framework of the dr. Bart app is presented. A central element of the dr. Bart app is that the app proposes a selection of 72 preformulated goals for health behaviours based on the tiny habits

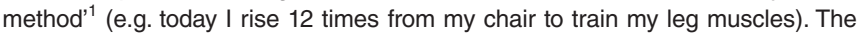
proposals are tailored to user characteristics and related to four themes that are core elements in the non-surgical management of OA. After a user completes one or more of the selected goals, a new selection is proposed by dr. Bart. A user can work on 3 goals simultaneously. Goals can be completed more than once by the same user. To assess the association between intensity of use of the app and health care utilization and clinical outcomes, we calculated Spearman rank correlation coefficients.

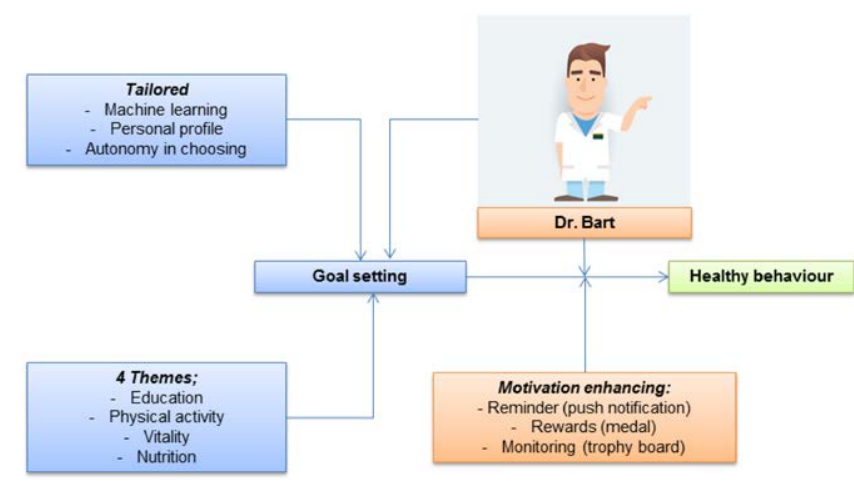

Figure 1. Theoretical framework of the dr. Bart app.

Results: 171 / 214 participants (80 \%) logged in at least once whilst 151 (71\%) chose at least one goal and $114(53 \%)$ completed at least one goal during the 26 weeks. Of those who chose at least one goal, 56 participants (37\%) continued to log in up to 26 weeks, 12 ( $8 \%$ ) continued to select new goals from the offered goals and $37(25 \%)$ continued to complete goals (Figure 2). Preformulated goals regarding the themes activity (e.g. performing an exercise from the exercises library of the app) and nutrition (e.g. eat 2 pieces of fruit today) were found to be most popular by users. We found no correlations between intensity of use and health care utilization and clinical outcomes.

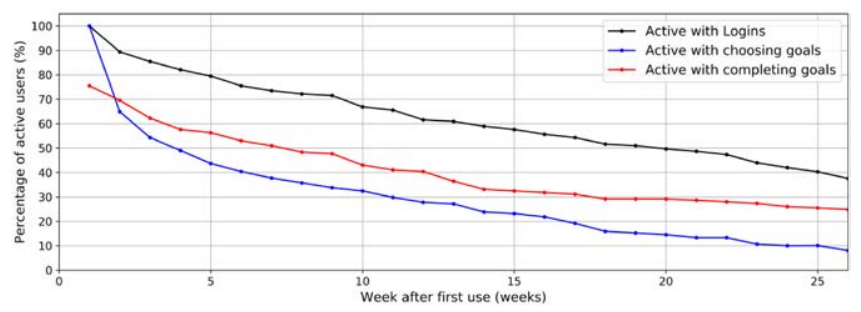

Figure 2. Percentage of active users ( $\mathrm{N}=151)$ over time.

Conclusion: A considerable proportion of persons with knee and/or hip OA persistently used the app up to 26 weeks. Patients appear to have preferences for goals related to activity and nutrition, rather than for goals related to vitality and education. We found no relation between intensity of use of the dr. Bart app and health care utilization and clinical outcomes.

\section{References:}

[1] Fogg GJ: A behavior model for persuasive design. In: Proceedings of the $4^{\text {th }}$ international Conference on Persuasive Technology: 2009: ACM; 2009: 40.

Disclosure of Interests: None declared

DOI: 10.1136/annrheumdis-2020-eular.1299

\section{FRI0630-HPR ONE-YEAR FOLLOW-UP OF A NURSE-LED TEAM INTERVENTION EFFECTIVE IN REDUCING THE NOCEBO EFFECT WHEN SWITCHING FROM ORIGINATOR INFLIXIMAB TO A BIOSIMILAR.}

J. Petit ${ }^{1}$, M. Antignac ${ }^{2}$, K. Louati ${ }^{1}$, S. Desouches ${ }^{1}$, N. Deparis ${ }^{3}$, R. Baratto ${ }^{1}$ R. Poilverd ${ }^{1}$, S. Dartout ${ }^{1}$, F. Berenbaum ${ }^{1}$, C. Beauvais ${ }^{1}{ }^{1}{ }^{H}$ Hopital Saint Antoine, APHP, Rhumatologie, Paris, France; ${ }^{2}$ Hôpital Saint Antoine, APHP, Pharmacie, Paris, France; ${ }^{3}$ Association Nationale de Défense contre LArthrite Rhumatoïde, Paris, France

Background: Nonspecific subjective adverse effects and symptoms (NSAE/ NSS), usually considered as related to a nocebo effect (NE), have been identified as a barrier to the acceptability of switches from biologic originators (BO) to biosimilars (BS) in rheumatology. A multidisciplinary team intervention with a prominent role of nurses has provided a reduction of the NE assessed in the short-term during a systematic switch from originator Infliximab $(\mathrm{OI})$ to the biosimilar infliximab SB2 (ref.1).

Objectives: To assess the intervention outcomes after one-year follow up in comparison with a historical cohort.

Methods: The intervention was developed after a literature search and semi-directive interviews of patients, and included consensual communication towards patients, with a prominent role of nurses (Ref.1). All patients with chronic inflammatory rheumatic diseases (CIRD) treated by OI were included and followed-up 
in routine care. The outcomes were I) SB2 retention rate (RR) II) SB2 discontinuation rate due to a presumed NE, defined as lack of efficacy with no objective criteria for increased inflammation or non-objective and non-specific adverse event, either occurring after the switch and disappearing after back-switch or change of biologic. Criteria for NSAE/NSS in the historical cohort were the same lack of efficacy or subjective adverse events and disappearance after change of biologic BD. Medium-term (12 months) SB2 outcomes were assessed and compared with I) the data obtained in the short-term (34 weeks) II) the data from an historical cohort of CIRD patients treated by OI in the same rheumatology department, using Kaplan-Meier survival curve.

Results: Forty-five patients were prospectively included for the switch from March 2018 to August 2018: 17 with rheumatoid arthritis (RA), 28 with spondylarthritis (SpA); $55 \%$ were women, mean age was 53.2 (SD: 2,1 ), and mean time under Ol was 113.5 (SD9.3). For the historical cohort, the 52 patients treated with OI between December 2016 and January 2017 were included and their data collected at baseline and one year. Fifty-nine percent were women, mean age at inclusion was 50.25 (1.2), and mean time under OI was 94.8 (9.4).

SB2 RR did not differ from the OI RR in the historical cohort: $91.2 \%$ and $96.2 \%$ respectively at 34 weeks ( $p=0.41$ ); $84.4 \%$ and $88.5 \%$ respectively at 12 months $(p=0.52$ ) (figure 1). The SB2 RR was significantly higher than in three other European cohorts at 34 weeks (mean RR 73.6\%, p<0.05, ref.1) but not at 12 months (mean RR $80.9 \%$, ref.2,3,4).

SB2 and OI discontinuations due to NSAE/NSS at 34 weeks were 2,2 \% and $1.9 \%$ respectively; at 12 months $6,6 \%$ and $1.9 \%$ respectively $(p=0.6)$.

Conclusion: An intervention based on a tailored communication with a prominent role of nurses was effective in reducing the NE when switching from OI to SB2 in the short term, compared with an historical cohort and other European cohorts. The one-year follow-up showed no statistical difference in RR or NE compared with our historical cohort. The present study shows that appropriate interventions may be developed to improve the outcome of switches to biosimilars.

Figure 1: Treatment withdrawal free survival curves (SB2 in switched cohort and $\mathrm{OI}$ in historical cohort).

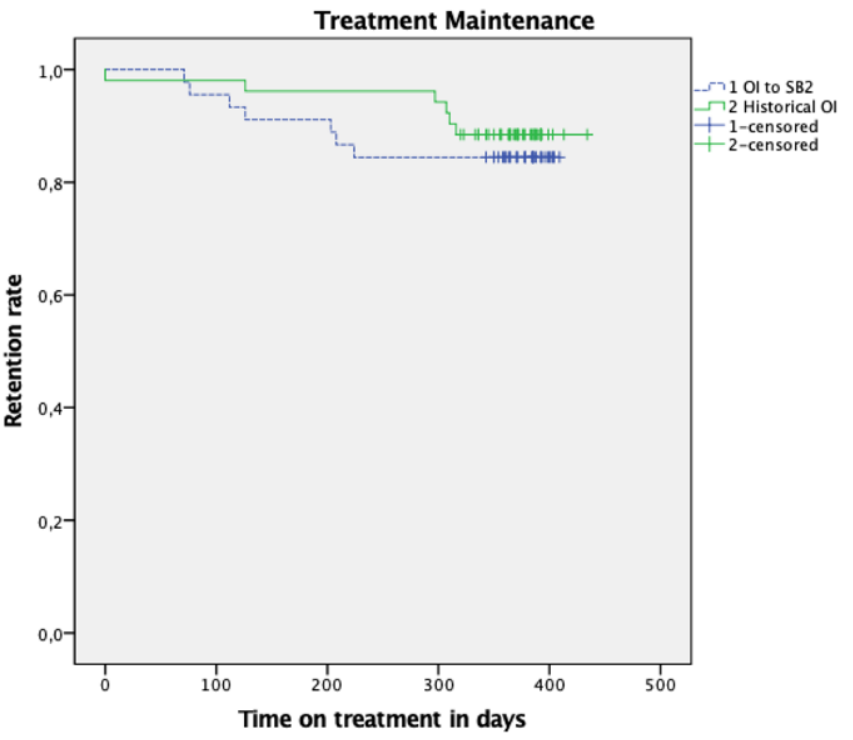

Kaplan Meir survival curves. Comparison with Log-Rank test between OI to SB2 cohort and historical OI cohort, $p=0.520$. OI : original infliximab.

\section{References:}

[1] Petit J. Ann Rheum Dis, volume 78, supplement 2, year 2019, page A1447

[2] Glintborg B. et al. Ann Rheum Dis 2017;76:1426-31.

[3] Nikiphorou E. et al. Expert Opin Biol Ther 2015;15:1677-83.

[4] Boone NW. et al. Eur J Clin Pharmacol 2018;:1-7.

Acknowledgments: Dr Margaux Boisson Service de rhumatologie du Professeur Kahan, Hôpital Cochin, APHP.

Disclosure of Interests: Juliette Petit: None declared, Marie Antignac: None declared, Karine Louati: None declared, Sandra Desouches: None declared, Nathalie DEPARIS: None declared, Regine Baratto: None declared, Rosemarie POILVERD: None declared, Sylvie Dartout: None declared, Francis Berenbaum Grant/research support from: TRB Chemedica (through institution), MSD (through institution), Pfizer (through institution), Consultant of: Novartis, MSD, Pfizer, Lilly, UCB, Abbvie, Roche, Servier, Sanofi-Aventis, Flexion Therapeutics, Expanscience, GSK, Biogen, Nordic, Sandoz, Regeneron, Gilead, Bone Therapeutics, Regulaxis,
Peptinov, 4P Pharma, Paid instructor for: Sandoz, Speakers bureau: Novartis, MSD, Pfizer, Lilly, UCB, Abbvie, Roche, Servier, Sanofi-Aventis, Flexion Therapeutics, Expanscience, GSK, Biogen, Nordic, Sandoz, Regeneron, Gilead, Sandoz, Catherine Beauvais Speakers bureau: Abbvie, MSD, Roche, UCB, Mylan, Sanofi DOI: 10.1136/annrheumdis-2020-eular.4388

\section{FRI0631-HPR SUPPLEMENTATION WITH CREATININE, GLUTAMINE AND B-HYDROXY-B-METHYLBUTYRATE IMPROVES MUSCLE MASS AND STRENGTH AND QUALITY OF LIFE IN PATIENTS WITH SARCOPENIA AND KNEE OSTEOARTHRITIS: THE DIMMUS RANDOMIZED STUDY}

H. Riera ${ }^{1}$, G. Colantuoni ${ }^{1}, \underline{M}$. Quintero ${ }^{1}$, F. Fernández ${ }^{2} .{ }^{1}$ Universidad de Los Andes- Servicio de Reumatología del Instituto Autónomo Hospital Universitario de Los Andes, Mérida, Venezuela (Bolivarian Republic); ${ }^{2}$ Service of Rheumatology, Clinica Razetti of Barquisimeto, Barquisimeto, Venezuela (Bolivarian Republic)

Background: Sarcopenia is characterized by progressive loss of muscle mass, strength, and physical function, and often accompanies other diseases such as osteoarthritis $(\mathrm{OA})^{1}$. Both conditions are also significantly associated with poor quality of life (QoL).

Objectives: A randomized controlled study was conducted to evaluate the effectiveness of creatinine, glutamine and $\beta$-hydroxy- $\beta$-methylbutyrate (HMB) supplementation in enhancing muscle mass and strength, physical function and QoL in adults with sarcopenia and knee OA.

Methods: Sixty-two patients aged 40 years and above with sarcopenia diagnosed according to the European Working Group on Sarcopenia and with knee OA according to the criteria of American College of Rheumatology were included in the study DIMMUS. The participants were randomly assigned into two groups of intervention $(n=31)$ and control $(n=31)$. The intervention group received oral nutritional supplementation daily plus standardized exercise programme for 12 weeks and the control group received only rescue analgesic medication and exercise training. Muscle mass (appendicular skeletal muscle mass index [ASMMI] estimated by the Baumgartner et al.'s equation), muscle strength (handgrip strength), physical function (4-m gait speed) and QoL (SARQoL) were measured before and after the 12-week intervention. Safety was also recorded by assessments of adverse events.

Results: There was no significant difference in baseline characteristics between the two groups $(85.5 \%$ women, $63.5 \pm 9.6$ years, body mass index of $26.8 \pm$ $4.5 \mathrm{~kg} / \mathrm{m}^{2}, 83.9 \%$ Kellgren-Lawerence grade II OA and $91.9 \%$ mild sarcopenia). A statistically significant improvement in the mean change of ASMMI $(3.7 \pm 1.0 \mathrm{~kg} /$ $\mathrm{m}^{2}$ to $\left.3.96 \pm 1.1 \mathrm{~kg} / \mathrm{m}^{2} ; P=0.0074\right)$, handgrip strength $(18.8 \pm 8.7 \mathrm{~kg}$ to $20.5 \pm$ $8.5 \mathrm{~kg}, P=0.0089)$, and SARQoL score $(59.3 \pm 8.8$ vs $70.7 \pm 16.6 ; P=0,0003)$ from baseline to 12 weeks was observed for the intervention group but not for the control group. Both groups showed significant improvements on 4-m gait speed $(5.0 \pm 0.9 \mathrm{~s}$ to $4.4 \pm 0.9 \mathrm{~s}$ in the intervention group; $5.2 \pm 2.9$ to $5.0 \pm 2.3 \mathrm{~m}$ in the control group; $P<0.001$ ). One patient reported a treatment-related bad taste in the intervention group.

Conclusion: The findings of the present study demonstrated that the combined supplementation of creatinine, glutamine and $\mathrm{HMB}$ together with exercise training for 12 weeks may have a positive effect on the muscle mass and strength and QoL in adults with mild sarcopenia and OA. The results provide preliminary experiences and guidance for further clinical trials in both $O A$ and sarcopenic patients. References:

[1] Kemmler W, Teschler M, Goisser S, Bebenek M, von Stengel S, Bollheimer LC,et al. Prevalence of sarcopenia in Germany and the corresponding effect of osteoarthritis in females 70 years and older living in the community: results of the FORMoSA study.Clin Interv Aging. 2015;10:1565-73.

Disclosure of Interests: None declared

DOI: 10.1136/annrheumdis-2020-eular.5777

\section{FRI0632-HPR PSYCHOLOGICAL PARTICULIARITIES OF PATIENTS SUFFERING FROM MONOGENIC AUTO- INFLAMMATORY DISEASES.}

N. Stepanenko ${ }^{1}$, E. Fedorov ${ }^{1}$, S. Salugina ${ }^{1}$, S. Feoktistova ${ }^{2} .{ }^{1}$ V.A.Nasonova Research Institute of Rheumatology, Pediatric, Moscow, Russian Federation; ${ }^{2}$ Russian New University (RosNOU), Psychology and Pedagogics, Moscow, Russian Federation

Background: Monogenic auto-inflammatory diseases (mAID) are a group of severe chronic multisystemic diseases with recurring episodes of fever and other manifestations that significantly affect the patients' life quality. Moreover, the hyper expression of pro-inflammatory cytokines (IL1 $\beta$, etc.) observed in these patients may have a negative effect on the central nervous system.

Objectives: to study the state of the cognitive and emotional spheres in children suffering from monogenic auto-inflammatory diseases. 